\title{
OPTIMASI INFRASTRUKTUR LAN PADA YAYASAN KESEHATAN (YAKES) TELKOM BANDUNG DENGAN MODEL CISCO THREE LAYER HIERARCHICAL MENGGUNAKAN METODOLOGI NETWORK DEVELOPMENT LIFE CYCLE (NDLC)
}

\author{
${ }^{1}$ Isnaini Hayati, ${ }^{2}$ Mochammad Teguh Kurniawan \\ ${ }^{1,2}$ Program Studi S1 Sistem Informasi, Fakultas Rekayasa Industri, Universitas Telkom \\ 1'isnaininay@student.telkomuniversity.ac.id, 2teguhkurniawan@telkomuniversity.ac.id
}

\begin{abstract}
Abstrak-Yayasan Kesehatan Telkom (Yakes Telkom) merupakan organisasi pengelola layanan kesehatan di bawah perusahaan Telekomunikasi Indonesia yang menggunakan infrastruktur LAN untuk mendukung tujuan organisasi. Jaringan saat ini terdiri dari satu router core yang terhubung ke switch layer 2 dan langsung terhubung ke end user (single link). Kondisi tersebut dapat menimbulkan permasalahan jika terjadi gangguan pada salah satu perangkat, maka mengakibatkan seluruh komputer tidak dapat terhubung karena tidak ada redundant link. Yakes Telkom juga belum menerapkan manajemen bandwidth sesuai kebutuhan pengguna jaringan. Cisco Three Layer Hierarchical Model dapat diterapkan dalam merancang infrastruktur LAN dengan membagi fungsi setiap perangkat jaringan berdasarkan lapisan core, distribution dan access. Network Development Life Cycle (NDLC) digunakan sebagai metode dalam perancangan infrastruktur LAN karena sifatnya yang berulang dan berkelanjutan untuk pengembangan infrastruktur jaringan suatu organisasi. Tahapan NDLC yang digunakan yaitu tahap Analysis, Design dan Simulation Prototyping. Penelitian ini menghasilkan rancangan infrastruktur LAN Yakes Telkom Bandung dengan menerapkan redundant link. Pengukuran QoS (Qouality of Service) dengan parameter throughput menghasilkan nilai untuk aplikasi kategori high $415.24 \mathrm{kbps}$, medium $251.37 \mathrm{kbps}$ dan low $82.56 \mathrm{kbps}$. Waktu delay yaitu $0.04 \mathrm{~s}$ masuk dalam kategori baik sesuai standar ITU-T G1010 (The International Telecommunication UnionTelecommunication) dan packet loss $0.32 \%$ sesuai standar TIPHON (Telecommunications and Internet Protocol Harmonization Over Network).
\end{abstract}

Kata Kunci: LAN, Cisco Three Layer Hierarchical Model, NDLC, QoS, redundant link, manajemen bandwidth, Yakes Telkom

\section{PENDAHULUAN}

Teknologi Informasi (TI) menjadi salah satu faktor utama yang harus dimiliki organisasi untuk mendukung setiap proses bisnis yang dilakukan. TI juga semakin berkembang khususnya dalam menyediakan infrastruktur jaringan dengan kecepatan tinggi didukung dengan adanya target pemerintah bahwa pada 1 Januari 2019 semua ibukota kabupaten dan kota seluruh Indonesia sudah terhubung dengan infrastruktur jaringan fiber optic [1]. Kebutuhan akan infrastuktur jaringan berkecepatan tinggi ini juga menyebar ke berbagai sektor pemerintahan khususnya sektor kesehatan. Adanya pertemuan menteri
Kesehatan dengan Menteri Komunikasi dan Informatika, peserta World Health Organization (WHO) untuk membahas kemajuan teknologi bidang kesehatan khususnya e-Health, memerlukan faktor pendukung salah satunya adalah teknologi dan ketersediaan jaringan dengan konektivitas yang tinggi untuk transaksi pertukaran data [2].

Yakes Telkom merupakan sebuah organisasi pengelola layanan kesehatan untuk memelihara kesehatan karyawan dan pensiunan Telkom beserta keluarganya. Yakes Telkom menggunakan TI berbasis komputer dan infrastruktur LAN untuk mendukung proses bisnis. Kondisi infrastruktur LAN Yakes Telkom saat ini masih menerapkan single link untuk menghubungkan setiap perangkat jaringan, belum adanya standardisasi terhadap penggunaan dan tata letak perangkat jaringan dan belum diterapkannya manajemen bandwidth untuk pengguna LAN pada Yakes Telkom.

Mengacu pada permasalahan tersebut, maka Yakes Telkom Bandung membutuhkan suatu rancangan topologi infrastruktur jaringan menggunakan Cisco Three Layer Hierarchical Model dengan membagi perangkat jaringan berdasarkan fungsinya. Pemilihan dan penempatan perangkat jaringan secara tepat merupakan salah satu faktor penting dalam membangun sebuah jaringan [3]. Network Development Life Cycle (NDLC) digunakan sebagai metode dalam perancangan infrastruktur jaringan LAN karena sifatnya yang berkelanjutan. Tahapan NDLC yang digunakan yaitu Analysis, Design dan Simulation Prototyping.

Penelitian ini bertujuan untuk mengetahui kondisi jaringan LAN saat ini pada Kantor Pusat Yakes Telkom. Kemudian melakukan perancangan desain jaringan LAN Yakes Telkom sesuai perkembangan teknologi informasi saat ini. Meningkatkan high availability pada jaringan LAN dengan menerapkan redundant link dan manajemen bandwidth yang sesuai dengan kebutuhan pengguna Kantor Pusat Yakes Telkom.

\section{STUDI LITERATUR}

\section{A. Jaringan komputer}

Pada umumnya jaringan komputer dibedakan berdasarkan rentang geografis dan dapat dibedakan menjadi 5 yaitu, LAN, 
MAN, WAN, PAN dan Internetwork [4]. Pada penelitian hanya menggunakan satu tipe jaringan komputer, yaitu LAN. Local Area Network (LAN) adalah sebuah jaringan komputer yang berada di dalam sebuah gedung dan dioperasikan di bawah sistem administrasi tunggal umumnya disebut sebagai Local Area Network ( $L A N)$. Biasanya, LAN mencakup daerah lokal pada jarak kurang dari $2 \mathrm{~km}$ meliputi bangunan tunggal seperti sebuah kantor, sekolah, perguruan tinggi atau universitas [4] . Jaringan LAN dengan menggunakan kabel mempunyai koneksi yang stabil sehingga ketika melakukan pertukaran data yang dilakukan akan berjalan lebih cepat sehingga akan meningkatkan peroformasi TI untuk perusahaan [5].

\section{B. Media transmisi}

Media transmisi adalah jalur fisik antara pengirim dan penerima untuk sebuah sinyal komunikasi. Beberapa jenis media transmisi adalah sebagai berikut:

\section{Twisted pair}

Twisted pair adalah yang paling sederhana dan paling murah dari media kabel yang lain dan memiliki rentang frekuensi untuk transmisi data serta transmisi suara $(100 \mathrm{~Hz}-$ $5 \mathrm{MHz})$.

\section{Fiber optic}

Fiber optic adalah teknologi komunikasi yang menggunakan media cahaya untuk mentransfer informasi dari satu titik ke titik lain melalui serat optik [6], terdapat tiga komponen dalam serat optik [7] seperti Gambar 1 sebagai berikut.

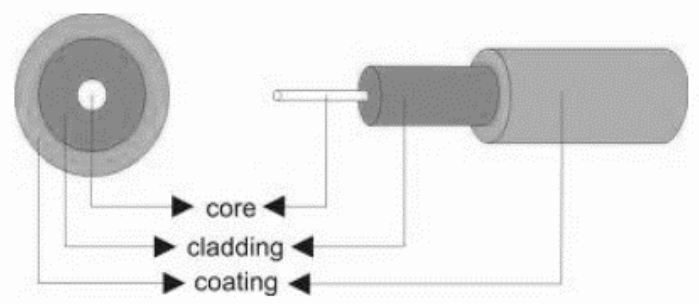

Gambar 1 Struktur dasar serat optik Sumber: [6]

a. Core merupakan bagian utama dari serat optik karena informasi berupa sinyal cahaya akan ditransmisikan.

b. Cladding atau bungkus adalah bagian yang melapisi core dan memiliki indeks bias yang lebih kecil daripada core.

c. Coating atau jaket adalah sebagai pelindung dari core dan cladding dari adanya tekanan fisik.

\section{Cisco three layer hierarchical model}

Cisco Three Layer Hierarchical adalah sebuah model untuk merancang desain antar jaringan yang kompleks menjadi lebih kecil dengan tujuan untuk memberi kemudahan dalam pengelolaan dan hemat biaya. Sebuah desain jaringan hierarchical akan membagi jaringan ke dalam lapisan yang terpisah dan setiap lapisan memiliki fungsi tertentu [8]. Cisco mendefinisikan tiga lapisan hierarchical model sebagai berikut [9].

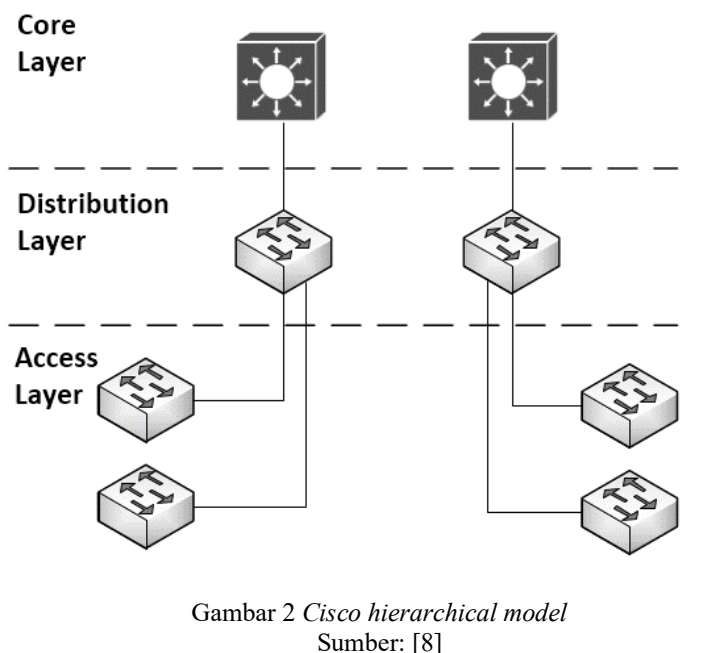

Gambar 2 menjelaskan struktur Cisco Three Layer Hierachical yang terdiri dari core, distribution dan access layer.

1. Core layer

Menyediakan konektivitas dengan kecepatan tinggi dengan skalabilitas yang luas. Layer ini sering disebut dengan backbone sehingga membutuhkan perangkat yang cepat karena setiap layer bergantung pada core layer ini.

\section{Distribution layer}

Merupakan penghubung antar access layer dan core laye yang berfungsi untuk melakukan packet filtering dalam mengatur pengiriman paket sesuai informasi sumber dan tujuan paket terebut.

3. Access layer

Menyediakan akses jaringan ke pengguna akhir seperti $P C$, printer dan sebagai pintu masuk pengguna ke dalam jaringan, access layer terkoneksi ke distribution layer.

\section{Quality of service (QoS)}

Quality of Service atau QoS adalah suatu persyaratan dalam layanan yang harus dipenuhi oleh jaringan untuk alur transportasi data dan memberikan layanan yang lebih baik [10]. QoS didesain agar pengguna mendapatkan performa yang sesuai dengan kebutuhan untuk menjalankan aplikasi pada jaringan. Parameter dalam QoS yaitu sebagai berikut [11]:

1. Delay

Waktu tunda untuk sebuah data menempuh jarak dari asal ke tujuan. Nilai delay dapat diketahui dengan melihat lama waktu yang digunakan dan total paket yang diterima, atau dengan rumus sebagai berikut.

$$
\text { Delay rata }- \text { rata }=\frac{\text { Total waktu }}{\text { Total paket yang diterima }}(1)
$$

Adapun rekomendasi waktu delay berdasarkan standar ITU-T G.1010 mengenai QoS dan performansi sesuai tingkat kenyamanan pengguna adalah sebagai berikut. 
TABEL I

REKOMENDASI ITU-T G. 1010 WAKTU DELAY

\begin{tabular}{|c|c|}
\hline Kategori & Waktu (ms) \\
\hline Baik & $0-150 \mathrm{~ms}$ \\
\hline Cukup & $150-300 \mathrm{~ms}$ \\
\hline Buruk & $>300 \mathrm{~ms}$ \\
\hline
\end{tabular}

Tabel I menunjukkan nilai untuk waktu delay yang dikategorikan oleh ITU-T.

\section{Throughput}

Jumlah total kedatangan paket dari sumber ke tujuan, dapat diartikan sebagai kecepatan (rate) transfer data yang efektif diukur dalam satuan bps (bit per second). Nilai throughput harus tinggi atau sesuai dengan tingkat layanan yang diberikan [12]. Rumus untuk menghitung nilai throughput adalah sebagai berikut.

$$
\text { Throughput }=\frac{\text { Jumlah data yang dikirim }}{\text { waktu pengiriman data }}
$$

\section{Packet loss}

Kondisi yang menggambarkan jumlah total paket yang hilang, dapat disebabkan adanya perlambatan pada jalur paketpaket data karena beban yang banyak mengakibatkan performansi menurun (congestion), dan disebabkan oleh terjadinya tabrakan data karena adanya pengiriman data secara bersamaan ke satu tujuan (collision) [13]. Berikut adalah rumus untuk mencari nilai packet loss.

\section{Packet Loss}

$=\frac{\text { (paket yang dikirim }- \text { paket yang diterima }}{\text { paket yang dikirim }} \times 100 \%$

Standar TIPHON tentang nilai packet loss dapat dikategorikan sebagai berikut:

TABEL II

REKOMENDASI TIPHON NILAI PACKET LOSS

\begin{tabular}{|c|c|}
\hline Kategori Degredasi & Packet Loss \\
\hline Sangat Bagus & $0 \%$ \\
\hline Bagus & $3 \%$ \\
\hline Sedang & $15 \%$ \\
\hline Buruk & $25 \%$ \\
\hline
\end{tabular}

Implementasi QoS dapat membantu dalam mengetahui kinerja suatu layanan jaringan. Dengan QoS, kita dapat mengetahui waktu delay pada saat pengiriman data, banyaknya paket yang hilang pada saat pengiriman dan memberikan rekomendasi terhadap bandwidth yang sesuai dengan kebutuhan jaringan.

\section{E. Network development life cycle (NDLC)}

Model yang digunakan untuk proses desain dan pengembangan sebuah infrastruktur jaringan dikenal sebagai Network Development Life Cycle (NDLC). Network
Development Life Cycle (NDLC) merupakan suatu metode yang digunakan dalam mengembangkan atau merancang jaringan infrastruktur yang memungkinkan terjadinya pemantauan jaringan untuk mengetahui statistik dan kinerja jaringan [14]. Kata "cycle" yang dalam Bahasa Indonesia berarti siklus merupakan kata kunci dalam pengembangan suatu jaringan karena menggambarkan sifat pengembangan suatu jaringan yang dilakukan secara kontinu atau berkelanjutan [12]. NDLC dibagi menjadi enam tahap seperti Gambar 3 yang dimulai dengan tahap analisis.

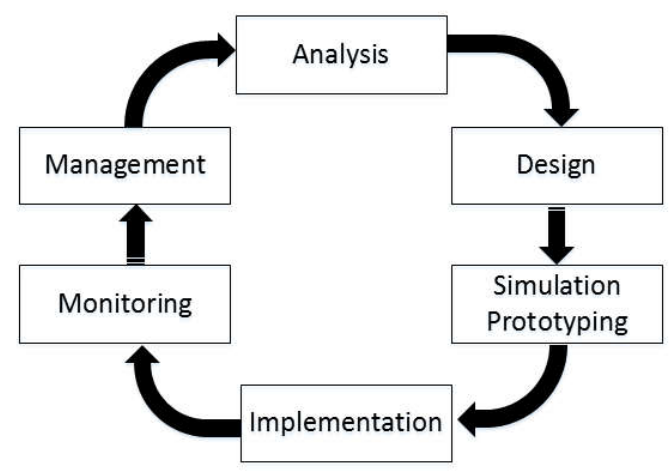

Gambar 3 Tahap NDLC

1. Analysis

Pada tahap awal ini dilakukan analisa kebutuhan, analisa permasalahan yang muncul, analisa keinginan pengguna, dan analisa topologi atau jaringan yang sudah ada saat ini. Metode yang biasa digunakan pada tahap ini diantaranya wawancara dan survey.

2. Design

Pada tahap design ini akan membuat gambar desain topologi jaringan yang akan dibangun, tujuan dengan adanya gambar ini akan memberikan gambaran seutuhnya dari kebutuhan yang ada.

3. Simulation prototyping

Pada tahap ini akan dibuat simulasi dengan bantuan tools khusus dibidang jaringan seperti Graphical Network Simulator 3 , tujuannya adalah untuk melihat kinerja awal dari jaringan yang akan dibangun.

\section{Implementation}

Pada tahapan implementasi ini akan memakan waktu lebih lama dari tahapan sebelumnya. Tahap ini akan menerapkan semua yang telah direncanakan dan di desain ditahap sebelumnya. Implementasi merupakan tahapan yang sangat menentukan berhasil atau tidak suatu rancangan yang akan dibangun.

\section{Monitoring}

Merupakan tahapan terpenting agar jaringan komputer dan komunikasi dapat berjalan sesuai dengan keinginan dan tujuan awal dari pengguna yang telah dijabarkan pada tahap analysis. 6. Management

Pada tahap ini yang menjadi perhatian khusus adalah masalah kebijakan untuk mengatur agar sistem yang telah dibangun dan berjalan dengan baik dapat berlangsung lama. Kebijakan tersebut tergantung pada kebijakan dari strategi bisnis perusahaan tersebut. 


\section{METODE PENELITIAN}

Model konseptual merupakan gambaran yang dibuat untuk memahami, melaksanakan, dan mengevaluasi penelitian sistem informasi. Tujuan dari model konseptual ini adalah sebagai acuan atau kerangka berfikir secara terstruktur untuk mencapai tujuan penelitian. Gambar 4 menjelaskan model konseptual dalam perancangan dan analisis Yakes Telkom Bandung berdasarkan kebutuhan penelitian knowledge based yang dapat diterapkan pada penelitian:
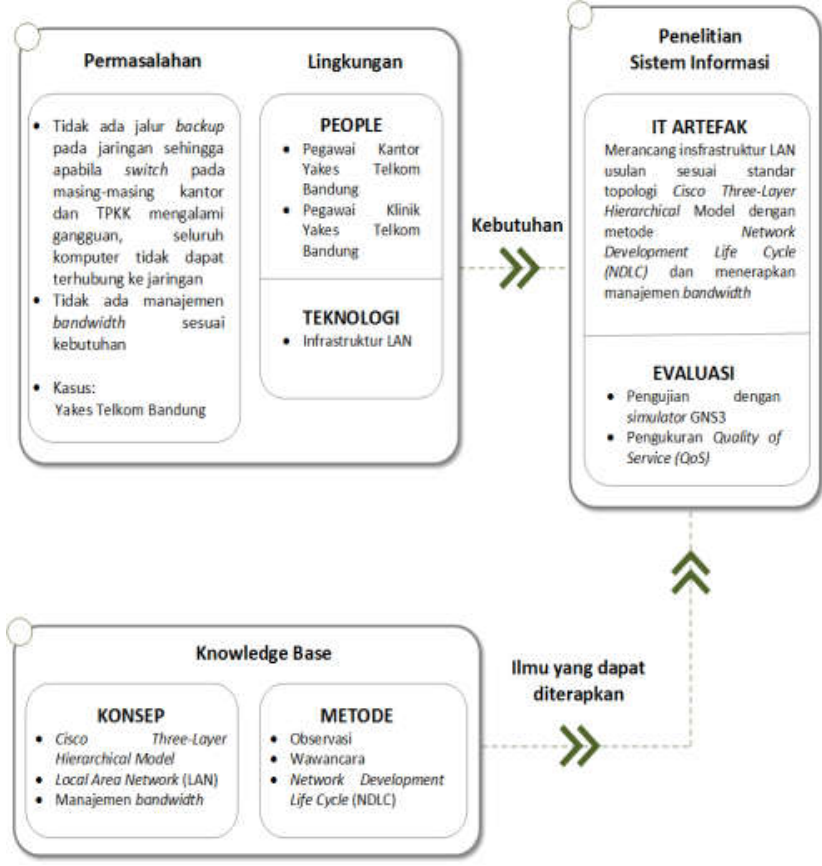

Penelitian ini akan menghasilkan sebuah rancangan infrastruktur jaringan LAN sesuai standar Cisco Three Layer Hierarchical Model Model menggunakan metode Network Development Life Cycle (NDLC).

\section{HASIL DAN ANALISIS}

A. Analisis desain jaringan saat ini

Pada Kantor Pusat Yakes Telkom terdiri dari 3 router yaitu router Intranet digunakan pengguna untuk terhubung ke jaringan luar menggunakan internet. Router Astinet digunakan untuk terhubung dengan pihak rumah sakit atau TPKU yang bekerja sama dengan Yakes Telkom, sedangkan router VPN digunakan pengguna untuk melakukan akses aplikasi yang berjalan pada Yakes Telkom. Gambar 6 menjelaskan desain infrastruktur LAN saat ini pada Kantor Pusat Yakes Telkom.

Pada Kantor Pusat memiliki satu buah switch pusat 3Com 3C16792 sebagai core untuk terhubung ke uplink VPN, Astinet dan Intranet, satu distribution switch untuk terhubung ke access switch yang ada pada tiap ruangan di Kantor Pusat. Pada Kantor Pusat juga terdapat server lokal milik Yakes Telkom yang terhubung dengan switch 1 Kantor Pusat dan server tersebut hanya dapat diakses oleh jaringan lokal (intranet).

Topologi LAN saat ini pada Yakes Telkom sudah menerapkan topologi Cisco Three Layer Hierarchical Model namun belum diterapkan rendundant link untuk mengantisipasi adanya gangguan pada salah satu link dan belum di dukung dengan perangkat jaringan yang sesuai dengan fungsi pada masing-masing layer. Selain itu juga belum diterapkan manajemen bandwidth yang sesuai dengan kebutuhan masingmasing pengguna pada Yakes Telkom.

Gambar 4 Model konseptual

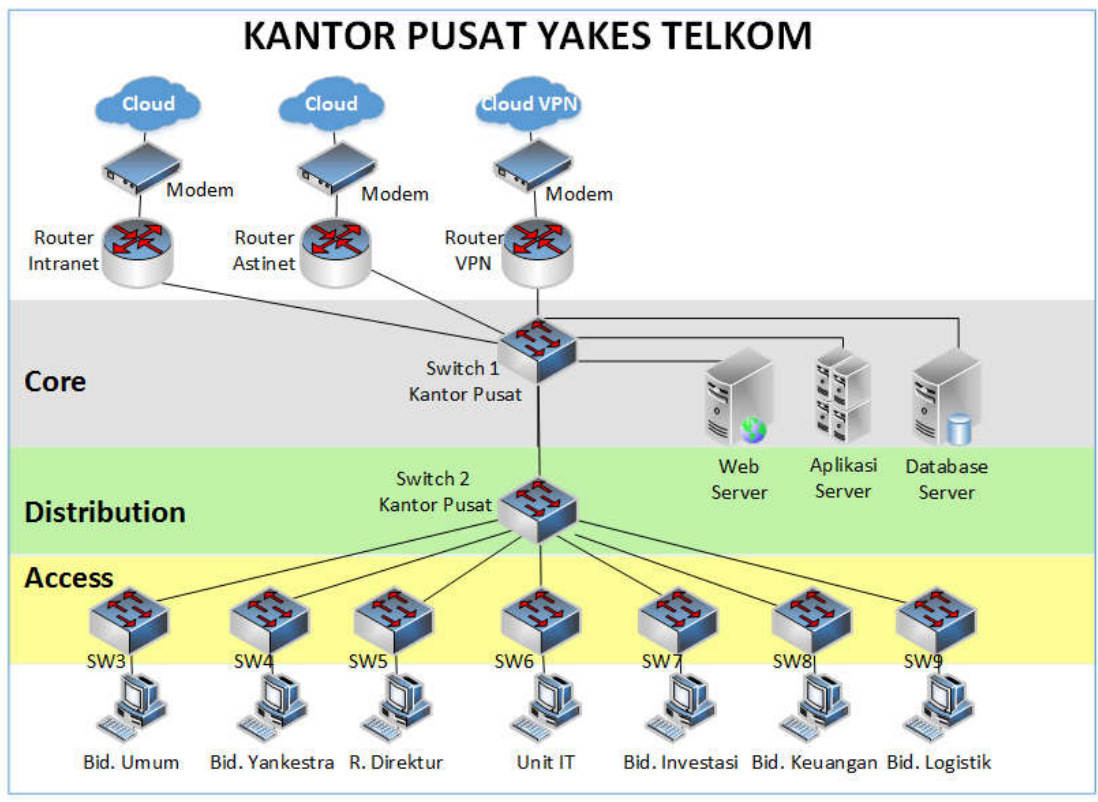

Gambar 5 Topologi jaringan saat ini 


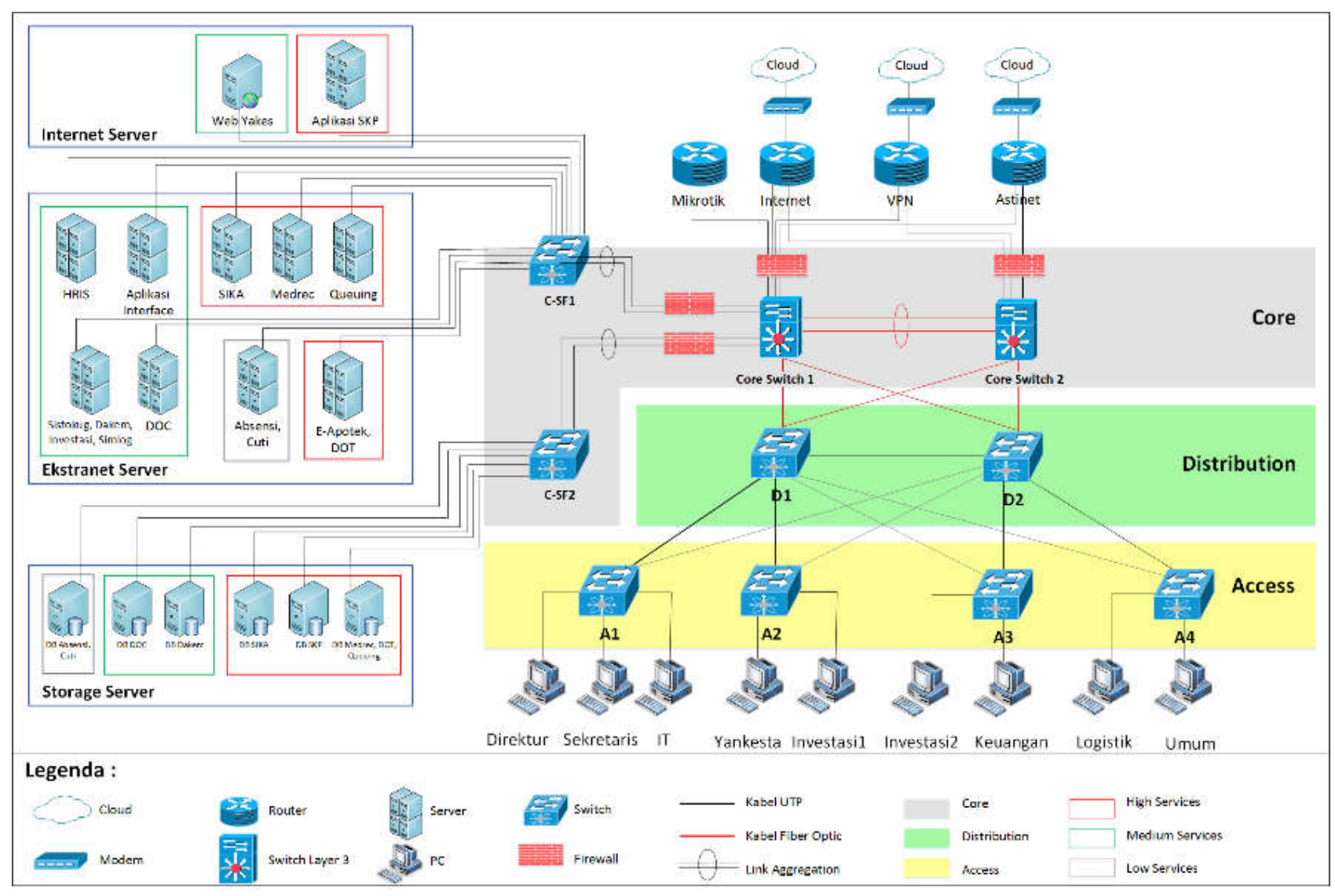

Gambar 6 Topologi jaringan usulan

B. Pengujian QoS Jaringan saat ini

Pengujian dilakukan dengan video streaming yang diakses oleh client pada waktu sibuk dan waktu senggang pada Kantor Pusat Yakes Telkom.

TABEL III

HASIL PENGUJIAN JARINGAN LAN SAAT INI

\begin{tabular}{|c|c|c|c|}
\hline \multicolumn{4}{|c|}{ Hasil Pengujian Kantor Pusat } \\
\hline Waktu Sibuk & $\begin{array}{c}\text { Throughput } \\
\text { (kbps) }\end{array}$ & Delay (s) & Packet Loss \\
\hline Rata-Rata & 266.38 & 0.039 & $0.92 \%$ \\
\hline $\begin{array}{c}\text { Waktu } \\
\text { Senggang }\end{array}$ & & & \\
\hline Rata-Rata & 216.57 & 0.039 & $0.86 \%$. \\
\hline
\end{tabular}

Tabel III menjelaskan hasil pengujian jaringan pada Yakes Telkom sudah dalam kondisi baik secara umum. Namun masih membutuhkan kebijakan agar kebutuhan bandwidth sesuai dengan kegunaan masing-masing aplikasi yang berjalan pada setiap divisi. Waktu delay $0.039 \mathrm{~s}$ setara dengan $39 \mathrm{~ms}$ menurut rekomendasi dari ITU-T waktu tersebut masuk dalam kategori bagus. Parameter $0-150 \mathrm{~ms}$ dikategorikan bagus sehingga dapat diterima oleh banyak pengguna aplikasi. Nilai packet loss ratarata dari hasil simulasi jaringan kurang lebih $0.89 \%$ termasuk dalam kategori bagus. Packet loss menurut TIPHON dikategorikan bagus jika nilai mencapai $0,1 \%$ - 3\%.
C. Perancangan desain jaringan usulan

Pengembangan topologi jaringan usulan yang dirancang berdasarkan kondisi jaringan saat ini pada Kantor Pusat Yakes Telkom. Gambar 7 menjelaskan desain jaringan usulan pada Kantor Pusat Yakes Telkom. Core layer merupakan bagian inti dari jaringan usulan untuk Kantor Pusat Yakes Telkom, menggunakan 2 buah perangkat multiyaler switch Cisco Catalyst 4503E dengan fungsi aggregation dan mendukung teknologi fiber optic. Penggunan 2 buah switch core diperlukan untuk redundancy perangkat apabila salah satu dari perangkat tersebut mengalami gangguan. Kemudian terdapat 2 switch Cisco Catalyst 3750 sebagai Core Server Farm (C-SF) untuk menampung server pada Yakes Telkom yang dibagi kedalam jenis Internet server dan ektranet server menggunakan C-SF1, sedangkan storage server pada C-SF2. Distribution layer menggunakan perangkat Cisco Catalyst switch 3750 untuk menerapkan redundant link dengan teknologi fiber optic untuk terhubung ke core layer. Sedangkan pada access layer menggunakan switch yang ada pada Yakes Telkom yaitu Cisco Catalys 2960. Berikut adalah tabel perangkat usulan untuk Core layer. Tabel IV menjelaskan perangkat LAN usulan pada core layer yaitu Cisco Catalyst 4503E. Sedangkan untuk perangkat distribution layer adalah sebagai berikut. 
TABEL IV

PERANGKAT JARINGAN CORE LAYER

\begin{tabular}{|l|l|}
\hline \multicolumn{1}{|c|}{ Parameter } & \multicolumn{1}{c|}{ Cisco Catalyst 4503E } \\
\hline Uplink interfaces & 100 Base-FX (fiber media) \\
\hline Connector Type & RJ-45, SFP, SFP+ Port \\
\hline Total Interfaces & 48 Port \\
\hline Modul expansion & Yes, (3 Modul with 48 Port/Modul) \\
\hline Feature & $\begin{array}{l}\text { OSPF, VLAN, BGP, Etherchannel, } \\
\text { QoS }\end{array}$ \\
\hline $\begin{array}{l}\text { Bandwitdh } \\
\text { Capacity }\end{array}$ & 480 Gbps \\
\hline Vendor & Cisco System \\
\hline
\end{tabular}

Tabel V menjelaskan perangkat LAN usulan pada distribution layer yaitu Cisco Catalyst 3750. Sedangkan untuk perangkat access layer adalah sebagai berikut.

TABEL V

PERANGKAT JARINGAN DISTRIBUTION LAYER

\begin{tabular}{|l|l|}
\hline \multicolumn{1}{|c|}{ Parameter } & \multicolumn{1}{c|}{ Cisco Catalyst 3750 } \\
\hline Uplink interfaces & $\begin{array}{l}\text { 24 Port and 4 Port Gigabit Ethernet } \\
\text { SFP-Based }\end{array}$ \\
\hline Connector Type & RJ-45, SFP, SFP+ \\
\hline Total Interfaces & 48 Port \\
\hline Modul expansion & No \\
\hline Feature & VLAN, STP, Etherchannel, QoS \\
\hline $\begin{array}{l}\text { Bandwitdh } \\
\text { Capacity }\end{array}$ & 48 Gbps \\
\hline Vendor & Cisco System \\
\hline
\end{tabular}

Tabel VI menjelaskan perangkat LAN usulan pada access layer yaitu Cisco Catalyst 2960.

TABEL VI

PERANGKAT JARINGAN ACCESS LAYER

\begin{tabular}{|l|l|}
\hline \multicolumn{1}{|c|}{ Parameter } & \multicolumn{1}{c|}{ Cisco Catalyst 2960 } \\
\hline Uplink interfaces & 24 Port SFP+10 GigabitEthernet \\
\hline Connector Type & RJ-45, SFP, SFP+ \\
\hline Total Interfaces & 48 Port \\
\hline Modul expansion & No \\
\hline Feature & VLAN, STP, Etherchannel, QoS \\
\hline $\begin{array}{l}\text { Bandwitdh } \\
\text { Capacity }\end{array}$ & 48 Gbps \\
\hline Vendor & Cisco System \\
\hline
\end{tabular}

\section{Analisis kebutuhan bandwidth}

Analisis kebutuhan bandwidth merupakan proses untuk menentukan kebutuhan bandwidth yang digunakan pada Yakes Telkom Bandung untuk memenuhi kebutuhan jaringan. Berdasarkan standar mengenai rekomendasi bandwidth dari Microsoft, bahwa dibutuhkan 1.5 sampai 3 Mbps bandwidth untuk kebutuhan akses user terhadap server, kecepatan bandwidth tersebut mencakup 100 hingga 10.000 user akses [13]. Selain itu juga dapat dilihat dari hasil analisis penggunaan bandwidth pada jaringan saat ini.
TABEL VII

HASIL ANALISIS PENGGUNAAN BANDWIDTH

\begin{tabular}{|c|l|c|}
\hline No. & \multicolumn{1}{|c|}{ Perangkat } & Bandwidth \\
\hline 1 & Router VPN Pusat & - \\
\hline & Server & $1.65 \mathrm{Mbps}$ \\
\hline & LAN Pusat & $236.09 \mathrm{Kbps}$ \\
\hline 2 & Server Aplikasi Medrec & $1.03 \mathrm{Mbps}$ \\
\hline 3 & Router VPN Area 3 & $1.17 \mathrm{Mbps}$ \\
\hline
\end{tabular}

Pada Tabel VII menjelaskan bahwa link yang mengarah ke server penggunaan rata-rata bandwidth yaitu $1.65 \mathrm{Mbps}$ dalam satu bulan, untuk seluruh aplikasi tanpa ada perbedaan kategori. Kemudian rata-rata bandwidth yang digunakan pada aplikasi Medrec yang masuk dalam kategori high adalah 1.03 Mbps.

Berdasarkan analisis tersebut maka dilakukan manajemen bandwidth untuk Kantor Pusat terhadap server yang dibagi dalam 3 tingkat kritikalitas yaitu high server diberikan maksimal bandwidth sebesar $2 \mathrm{Mbps}, 1 \mathrm{Mbps}$ untuk medium server dan $512 \mathrm{KBps}$ untuk low server.

E. Hasil analisis desain jaringan usulan

Pengujian jaringan usulan dilakukan dengan simulator GNS3 dan client melakukan video streaming yang disediakan oleh server. Kemudian wireshark melakukan capture packet untuk dianalisis QoS pada jaringan usulan tersebut dan menghasilkan nilai pada parameter throughput, delay dan packet loss sesuai standar ITU-T dan TIPHON.

Hasil pengujian jaringan usulan Kantor Pusat Yakes Telkom dengan diterapkannya manajemen bandwidth maka untuk akses server berdasarkan kategori kritikalitas aplikasi pada Yakes Telkom yaitu kategori high, medium dan low sudah sesuai dengan kebutuhan masing-masing kategori tersebut. Hasil pengujian QoS pada jaringan usulan adalah sebagai berikut:

1. Parameter pengujian yaitu troughput, packet loss dan delay menunjukkan nilai yang baik sesuai standar ITU-T. Hasil pengujian menunjukkan throughput untuk kategori high adalah $415.24 \mathrm{kbps}$, kategori medium $251.37 \mathrm{kbps}$ dan kategori low 82.56 kbps. Hasil tersebut menunjukkan bahwa setiap pengguna yang terhubung ke jaringan akan membutuhkan bandwidth yang sesuai dengan kebutuhan dan akitivas kerja yang dilakukan. Alokasi bandwidth juga memengaruhi proses komunikasi dalam jaringan tersebut [15].

2. Nilai delay pada jaringan usulan rata-rata $0.04 \mathrm{~s}$ masuk dalam kategori baik dan masih dapat diterima oleh pengguna aplikasi menurut standar ITU-T. Parameter packet loss dengan nilai rata-rata $0.32 \%$.

3. Berdasarkan poin (1), semakin kecil nilai packet loss dan delay yang diperoleh maka nilai throughput yang dihasilkan akan lebih besar.

F. Aspek tingkat layanan jaringan

Topologi jaringan usulan Yakes Telkom Bandung mengacu pada tiga parameter yaitu availability, quality of service dan manageability. 


\section{Availability}

Pada topologi jaringan usulan sudah diterapkan redundant link untuk menyediakan jalur cadangan apabila terjadi gangguan pada jalur utama yang memengaruhi availability atau ketersediaan layanan informasi yang dibutuhkan oleh end user.

\section{Quality of services (QoS)}

QoS di desain untuk membantu pengguna menjadi lebih produktif dengan memastikan bahwa pengguna mendapat informasi yang handal dari aplikasi berbasis jaringan [18].

Hasil pengujian topologi jaringan usulan tersebut fokus pada manajemen QoS yaitu pembagian bandwidth sesuai dengan kebutuhan masing-masing link. Khususnya untuk server yang terbagi dalam tiga kategori yaitu high, medium dan low yang membutuhkan perlakuan yang berbeda terhadap kebutuhan bandwidth. Pada server dengan kategori high diberikan alokasi bandwidth sebesar 2 Mbps karena menampung aplikasi yang berjalan secara realtime pada Yakes Telkom, untuk kategori medium adalah server yang menampung aplikasi yang mendukung proses bisnis Yakes Telkom umumnya yang terkait dengan aplikasi internal. Kategori medium diberikan bandwidth sebesar 1 Mbps. Sedangkan untuk kategori low diberikan alokasi bandwidth sebesar 512 Kbps.

\section{Manageability}

Pada jaringan usulan parameter manageability diterapkan pada topologi Kantor Pusat Yakes Telkom di core layer. Terdapat 2 buah switch core server farm (C-SF) yang membagi server dalam kategori Internet server, Ekstranet server dan Storage server. Perangkat switch tersebut memisahkan link untuk Internet server dan Ekstranet server yang berada pada core server farm (C-SF1), sedangkan untuk Storage server pada C-SF2.

\section{KESIMPULAN}

Berdasarkan penelitian yang telah dilakukan maka hasil identifikasi dan analisis jaringan LAN pada Kantor Pusat Yakes Telkom adalah tidak adanya redundant link yang disediakan sehingga apabila jalur utama mengalami gangguan akan berdampak pada end user sebagai pengguna jaringan. Topologi jaringan saat ini juga belum menerapkan management bandwidth untuk mengalokasikan bandwidth sesuai kebutuhan layanan jaringan. Hal tersebut menyebabkan tidak adanya jaminan prioritas bandwidth untuk beberapa aplikasi yang bersifat kritis.

Hasil analisis dan perancangan desain jaringan usulan pada Kantor Pusat Yakes Telkom menggunakan metode NDLC karena dapat mendukung pengembangan yang berkelanjutan terhadap jaringan LAN sesuai kebutuhan Kantor Pusat Yakes Telkom. Perancangan infrastruktur jaringan LAN sesuai dengan Cisco Three Layer Hirarchical Model terdiri dari core, distribution dan access layer yang membagi penggunaan perangkat sesuai fungsi pada masing-masing layer. Penerapan konsep ini juga dapat memenuhi faktor availability dan manageability pada suatu jaringan.

Manageability perangkat dilakukan pada server yang dikategorikan dalam 3 bagian yaitu Internet server, ekstranet server dan storage server untuk mempermudah pengelolaan perangkat jaringan. Skenario pengujian video streaming dengan pengukuran nilai QoS.

TABEL VIII

HASIL PENGUJIAN JARINGAN USULAN

\begin{tabular}{|c|c|c|c|c|}
\hline \multicolumn{5}{|c|}{ Hasil Pengujian Kantor Pusat } \\
\hline \multirow{2}{*}{ Parameter } & \multirow{2}{*}{$\begin{array}{c}\text { Jaringan } \\
\text { Eksisting }\end{array}$} & \multicolumn{3}{|c|}{ Jaringan Usulan } \\
\cline { 3 - 5 } & 241.48 & 415.24 & 251.37 & 82.56 \\
\hline $\begin{array}{c}\text { Throughput } \\
\text { (kbps) }\end{array}$ & & 0.041 & 0.040 & 0.039 \\
\hline Delay (s) & 0.040 & $0.36 \%$ & $0.34 \%$ & $0.27 \%$ \\
\hline Packet Loss & 0.89 & 0 & & \\
\hline
\end{tabular}

dari parameter throughput sesuai kebutuhan akses aplikasi yang dibagi dalam 3 kategori high dengan rata-rata 415.24 kbps, medium 251.37 kbps dan low 82.56 kbps. Parameter delay dengan rata-rata $0.04 \mathrm{~s}$ atau $40 \mathrm{~ms}$ masuk dalam kategori baik sesuai standar ITU-T G1010 dengan rentang waktu 0-150 ms. Parameter packet loss dengan rata-rata $0.32 \%$ masuk dalam kategori bagus sesuai standar TIPHON dengan batas maksimal packet loss adalah 3\%, sudah lebih baik dari jaringan eksisting yang mencapai $89 \%$.

\section{DAFTAR PUSTAKA}

[1] Kemkominfo, "Berita Kementerian," 18 April 2016. [Online]. Available: https://www.kominfo.go.id/content/detail/7296/1januari-2019-seluruh-wilayah-indonesia-terhubungfiber-optik/0/berita_satker.

[2] Kemkominfo, "Berita Kementerian," 27 Mei 2016. [Online]. Available: https://www.kominfo.go.id/content/detail/7529/digitalhealth-untuk-kesejahteraan-semua/0/berita_satker.

[3] M. T. Kurniawan, A. Nurfajar, O. Dwi and U. Yunan, "Desain Topologi Jaringan Kabel Nirkabel PDIILIPIdengan Cisco Three-Layered Hierarchical menggunakan NDLC," ELKOMIKA, vol. 4, p. 58, 2016.

[4] Tutorialspoint, Learn DCN (Data Communication and Computer Network), Tutorials Point, 2014.

[5] A. Kurniastuti, "Mengenal Jaringan LAN (Local Area Network)," Jurnal Matematika dan Komputer, p. 136, 2001.

[6] A. Nurfajar, M. T. Kurniawan and U. Y. K. S.H., "Desain dan Analisa Infrastruktur Jaringan Wired di PDII-LIPI Jakarta dengan menggunakan metode Network Development Life Cycle (NDLC)," Open Library Telkom University, p. 1, 2015.

[7] A. Dasari, "Optical fiber Communication Evolution,Technology and Future Trends," Journal of The International Association of Advanced Technology and Science, p. 1, 2015.

[8] M. Sulaiman, N. Ubay and Suhata, "Sistem Komunikasi Serat Optik Data Satelit," Berita Dirgantara Vol. 15 No. 2, pp. 59-60, 2015. 
[9] Cisco Network Academy, "Connecting Networks Companion Guide 1st Edition," in Hierarchial Network Design, Cisco Press, 2014, p. 2.

[10] T. Lammle, CCNA Cisco Certified Network Associate Deluxe Study Guide 6th Edition, Sybex Serious Skills, 2011.

[11] S. R. Vegesna, IP Quality of Service 1st Edition, Cisco Press, 2001.

[12] P. E. Pratiwi, A. F. Isnawati and A. Hikmaturokhman, "Analisi QoS Pada Jaringan Multi Protocol Label Switching (MPLS) Stuci Kasus di Pelabuhan Indonesia III Cabang Tanjung Intan Cilacap," p. 3, 2012.

[13] V. Mehta and D. N. Gupta, "Performance Analysis of QoS Parameter for Wimax Network," IJEIT, vol. 1, no. 5, p. 107, 2012.

[14] Prabowo, R., \& Kurniawan, M. (2015). ANALISIS DAN DESAIN KEAMANAN JARINGAN KOMPUTER DENGAN METODE NETWORK DEVELOPMENT LIFE CYCLE (STUDI KASUS: UNIVERSITAS TELKOM). Jurnal Rekayasa Sistem \& Industri (JRSI), 2(01), 1-7.

[15] M. Fathinuddin, M. T. Kurniawan and A. Kurniawati, "Perancangan Topologi Jaringan Pada Pemerintah Kabupaten Bandung dengan Metodologi NDLC menggunakan GNS3," SENTIA, vol. 6, pp. B-192, 2014. 